\title{
TUBE-JACK TESTING FOR IRREGULAR MASONRY WALLS: REGULAR MASONRY WALL TESTING
}

Elizabeth Manning

PhD Candidate, ISISE, University of Minho, Guimarães, Portugal, mann0211@umn.edu, 1-651-808-5986, corresponding author

Luís F. Ramos

Assistant Professor, ISISE, University of Minho, Guimarães, Portugal, lramos@civil.uminho.pt

Francisco M. Fernandes

Assistant Professor - PhD, ISISE, Lusiada University, Vila Nova Famalicão, Portugal, francisco.fernandes@fam.ulusiada.pt

\begin{abstract}
This paper presents the continued development of a novel non-destructive testing method termed tube-jack testing. The goal of the tube-jack system is to provide an enhanced and less destructive method than traditional flat-jack testing for determination of mechanical characteristics and local stress states in irregular masonry walls. Single tubejack tests were performed, using previously developed rubber tube-jacks, in regular masonry walls of granite and cement-lime mortar. A traditional flat-jack test was also performed in the same masonry wall. Conclusions suggest that tube-jacks are successful in applying pressure to the masonry at low stress states.
\end{abstract}

KEYWORDS: Tube-jack Testing, Flat-jack Testing, NDTs, Unreinforced Masonry, Experimental Testing

\section{ACKNOWLEDGEMENTS}

The authors would like to acknowledge the Fundação para a Ciência e Tecnologia, which supported this research work as a part of the Project "Improved and innovative techniques for the diagnosis and monitoring of historical masonry", PTDC/ECM/104045/2008.

\section{INTRODUCTION}

In the structural analysis of existing unreinforced historical masonry structures, there are few options for determining the mechanical characteristics of the masonry. Often the structure has no documentation indicating what 
properties were required or obtained in its construction. Even if the mechanical characteristics are documented, changes and damages to the structure are likely to have occurred over time [1]. Thus, it is necessary to determine the mechanical properties in another way in order to complete an analysis of the structure.

Nondestructive and minor destructive testing techniques are the most direct methods of determining mechanical characteristics of existing unreinforced masonry, when load tests of the structure and material tests of extracted masonry samples are not possible. The flat-jack test method is a standardized test method used for determining the local stress state in unreinforced masonry [2]. Unfortunately, flat-jack testing can cause some damage to the historic masonry that is to be protected [3] and the results are difficult to interpret or even unreliable when testing typologically irregular masonry [4].

In an effort to develop methods that are less destructive to the historical structure and which can provide more reliable information about the characteristics of the structure and with greater accuracy, an enhanced method termed "Tube-Jack Testing" is under development at the University of Minho [3]. The method relies on the same principles as the widely used flat-jack test method [2] to determine the local state of stress in a masonry element, the modulus of elasticity, an estimation of the Poisson's ratio, and, whenever is possible, the masonry compressive strength. This paper will focus only on the tube-jack and flat-jack tests' use for the determination of the local state of stress in regular masonry elements.

The principle applied in both flat-jack and tube-jack testing to find the state of stress in the masonry can be described as follows. A slot or series of holes (opening) is drilled in the mortar joint of a masonry element, perpendicular to the assumed direction of compressive stress. This relieves the stress where the opening is created. As the stresses redistribute in the masonry, the opening closes slightly. The closure of the opening is measured using reference points that are selected on either side of the opening. Jacks are then inserted into the opening and inflated. The pressure in the jacks is increased until the distance between the reference points returns to the measured distance before the opening was made. The pressure in the jacks can then be correlated to the stress in the masonry element at that location, see [2] and [5] for details.

The tube-jack testing technique was first proposed by Ramos and Sharafi [6]. In their study, a comparison of the flat-jack and the tube-jack tests was conducted with a finite element model of a homogeneous wall. The results 
showed that the tube-jack test produced a more even stress distribution in the wall and obtained a reasonably accurate estimation of the compressive stress in the wall, thus providing a numerical validation of the method. Initial prototype development and testing was performed by Ramos et al. [3] and Manning et al. [7]. This development included the construction and testing of PVC, rubber and latex tube-jacks, initial testing of the tube-jacks in a twoblock specimen, and testing of fabric socks to confine the expansion of the tube material. The final results of this testing indicated that the final prototypes developed required testing in larger masonry specimens.

This paper presents continued work in the development of the tube-jack test method. Section 1 is an introduction to the tube-jack test method. Section 2 describes the updated tube-jack system and the theory behind the method. Section 3 gives background information on the masonry used for testing the tube-jack system, including mechanical characterization of the materials. Section 4 presents results from laboratory tests performed in a granite masonry wall. Section 5 presents results from a flat-jack test performed in the same masonry wall as the tube-jack tests. Comparisons between the tests, future work, and final conclusions are presented in Section 6.

\section{TUBE JACK SYSTEM DESCRIPTION AND THEORY}

The tube-jack system consists of a series of tube-jacks, forming an equivalent flat-jack, connected to a water pump via connection bars (see Figure 1). Linear variable displacement transducers (LVDTs) are placed at regular intervals between the tube-jacks to measure the relative displacement of the masonry throughout the test; including drilling, stress redistribution, tube-jack insertion, and pressurization phases (see Figure 1c). A data acquisition system and computer are used to record the water pressure in the tube-jack system and the LVDT data throughout the test.

A preliminary test of the tube-jack system using compressed air was performed in the $2^{\text {nd }}$ horizontal joint of the wall used for the tests presented in this paper. The air compressor capacity was 6 bars $(0.6 \mathrm{MPa})$. After reductions due to the pressure required to inflate the tube-jacks, area of the tube-jacks applying pressure to the masonry, and pressure losses throughout the system due to leaking air, the compressed air tube-jack system was unable to apply enough pressure to the masonry to return the displacements to zero. Thus, the switch was made to a water pressure system to obtain higher pressures, with a maximum working pressure range of 50-60 bars. 


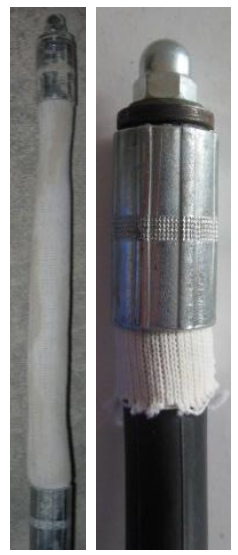

(a)

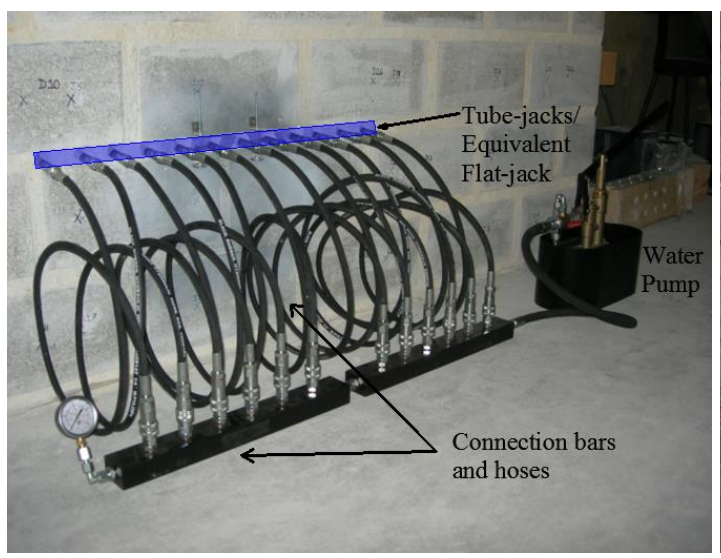

(b)

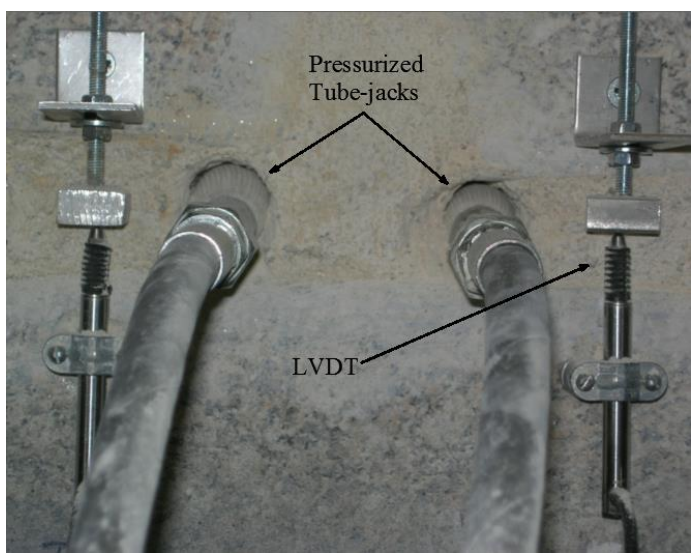

(c)

Fig. 1 Tube-jack test system components: (a) tube-jack; (b) tube-jacks forming an equivalent flat-jack, connection bars and hoses, water pump; and (c) pressurized tube-jacks and LVDTs for measuring displacements

The determination of how much pressure the tube-jacks apply to the masonry is more complex than for the flat-jacks because of the cylindrical shape of the holes and tube-jacks. Consider a tube situated along axis $z$ as shown in Figure 2a. The tube has an inner radius $a$ and an outer radius $b$. The initial thickness of the tube wall is $t_{i}=b-a$ when no pressures are exerted on the tube. The Young's modulus, $E$, and Poisson ratio, $v$, must be known for the tube material for this calculation. The tube is subject to internal water pressure $p_{w}$ and external masonry pressure $p_{m}$ as shown in Figure 2b. Due to these pressures, the tube will deform radially so that the new inner radius is $c$ and the outer radius is $d$. The unknowns that must be determined are the external masonry pressure, $p_{m}$, and the deformed inner radius of the tube, $c$, required for calculation of $p_{m}$.

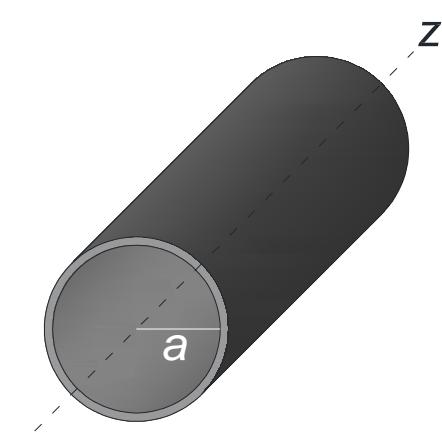

$Z$

(a)

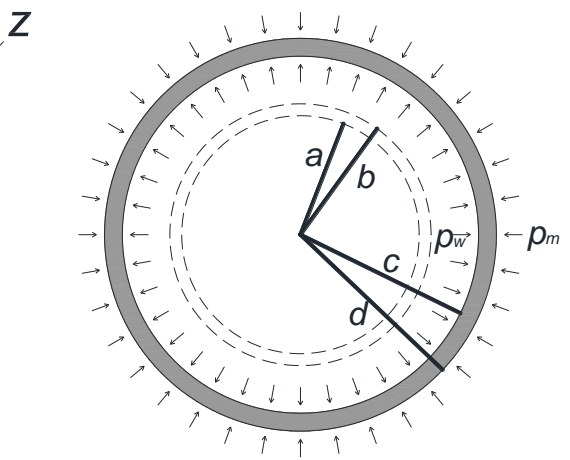

(b)

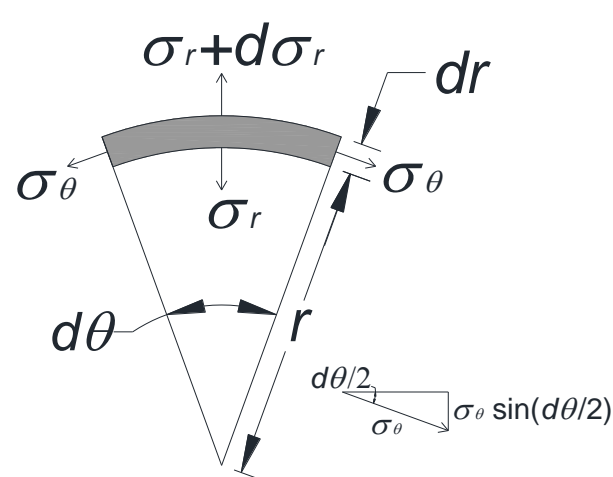

(c)

Fig. 2 Calculation of the pressure applied to the masonry: (a) tube before pressures are exerted on it; (b) sections of the original unstressed tube (dashed) and deformed tube under pressures $p_{w}$ and $p_{m}$; and (c) small element within the thickness of the tube

In the deformed tube, the radial pressure through the wall of the tube will vary between $p_{w}$ and $p_{m}$. Consider a small element within the thickness of the tube as shown in Figure 2c. This element is located at radius $r$ and has a thickness $d r$ and length $d z$ along the axis of the tube. The radial dimension of the element is $r d \theta$ at radius $r$. Since the 
pressure varies through the thickness of the tube there is a radial stress $\sigma_{r}$ at radius $r$ on the element. A slightly different stress $\sigma_{r}+d \sigma_{r}$ would act at the other edge of the element at radius $r+d r$. To satisfy equilibrium, the stress difference results in a tangential or hoop stress $\sigma_{\theta}$ [8]. By circular symmetry, the stresses $\sigma_{\theta}$ and $\sigma_{r}$ are functions only of $r$. Thus, there are no shear stresses in the tube. Considering equilibrium of forces in the radial direction and performing several mathematical operations yields the radial and tangential stresses at a radius $r$ within the thickness of the tube. These Equations, Eq. (1) and Eq. (2), are known as Lamé's equations [8].

$$
\begin{aligned}
& \sigma_{r}=\frac{p_{m} c^{2}-p_{w} d^{2}}{c^{2}-d^{2}}+\frac{c^{2} d^{2}\left(p_{w}-p_{m}\right)}{c^{2}-d^{2}} \frac{1}{r^{2}} \\
& \sigma_{\theta}=\frac{p_{m} c^{2}-p_{w} d^{2}}{c^{2}-d^{2}}-\frac{c^{2} d^{2}\left(p_{w}-p_{m}\right)}{c^{2}-d^{2}} \frac{1}{r^{2}}
\end{aligned}
$$

Consider the axial stress in the tube, $\sigma_{z}$. In the case of the tube-jack, the bolt inside the tube-jack resists the longitudinal expansion of the tube. Thus, the axial stress in the tube away from the ends of the tube may be assumed as zero. Therefore, Hooke's Law for the tangential stress in the tube becomes:

$$
\sigma_{\theta}=E \varepsilon_{\theta}+v \sigma_{r}
$$

Since at radius $r=d$, the exterior of the cylinder, $\sigma_{r}=-p_{m}$, inserting Eq. (1) and Eq. (2) into Eq. (3) and rearranging to solve for the external masonry pressure, $p_{m}$, yields:

$$
p_{m}=\frac{E \varepsilon_{\theta}\left(c^{2}-d^{2}\right)+2 p_{w} c^{2}}{c^{2}+d^{2}+v\left(c^{2}-d^{2}\right)}
$$

The tangential strain, $\varepsilon_{\theta}$, at radius $r=d$ depends on the stressed and unstressed circumference of the tube:

$$
\varepsilon_{\theta}=\frac{2 \pi d-2 \pi b}{2 \pi b}=\frac{2 \pi(d-b)}{2 \pi b}=\frac{d-b}{b}
$$

The radial strain, $\varepsilon_{r}$, can be determined based on the initial thickness, $t_{i}$, and final thickness, $t_{f}=d-c$, of the tube: 


$$
\varepsilon_{r}=\frac{t_{f}-t_{i}}{t_{i}}=\frac{(d-c)-(b-a)}{(b-a)}
$$

Inserting Eq. (5) and Eq. (6) into the equation for the Poisson ratio and rearranging to solve for the inner radius of the deformed tube, $c$, gives:

$$
c=\frac{v(d-b)(b-a)}{b}+a-b+d
$$

Eq. (7) can be inserted into Eq. (4) to determine the external masonry pressure, $p_{m}$, in terms of all known values. The external masonry pressure on the tube is equal in value and opposite in direction to the pressure the tube applies on the masonry, so the variable $p_{m}$ will be used for this quantity as well.

The water pump applies equal pressure to all of the tube-jacks during the pressurization. The line of tube-jacks forms an "equivalent" flat-jack that applies pressure to the masonry mostly perpendicular to the line of the tubejacks (see Figure 1b and Eq. (4)). One particular advantage of this system is that the application of the pressure at discrete intervals at each of the holes, instead of a single flat-jack, allows the holes to be drilled and the tube-jacks inserted into nonlinear mortar joints. The non-linearity of the jacks could change the direction of the applied pressure from that calculated in the equations above. Further research should be done to see how much effect deviations of the tube-jacks will have on the applied pressure. Thus, this system has the potential for application in irregular masonry typologies. In addition, the flexibility of this system allows the length of the line of tube-jacks to be varied by changing the number of tube-jacks used in the test. Thus, masonry with large stones, which could not be accurately tested with the fixed size flat-jacks, could be tested with the tube-jack system by increasing the number of tube-jacks and the length of the "equivalent flat-jack".

An estimation of the local state of stress within the masonry can be accomplished with a formula similar to the one used for flat-jack testing [2] and [5], which is presented in Eq. (8).

$$
\sigma_{m}=k_{a} p_{m}
$$


where: $\sigma_{m}=$ local state of stress in the masonry, $k_{a}=$ area correction factor, and $p_{m}=$ the pressure applied to the masonry at the point when the average relative displacements are restored to zero, i.e., the state before the holes were drilled. In this work the area correction factor has been multiplied by the pressure applied to the masonry to obtain the Applied pressure, $p_{\text {Applied. }}$ Thus, at the point when the average relative displacements are restored, the Applied pressure gives an estimate of the local state of stress in the masonry. Note that in Eq. (8) there is no jack calibration factor, as there is in the flat-jack test. This is because the properties of the tube material are taken into consideration in the calculation of the applied pressure. The area correction factor for single tube-jack tests using only one line of tube-jacks can be determined using Eq. (9).

$$
k_{a}=\frac{A_{T}}{A_{H}}
$$

where: $A_{T}=$ total surface area of tube-jacks in contact with and applying pressure to the masonry projected on a plane through the centroid of the tube-jacks, and $A_{H}=$ total cross-sectional area of the holes drilled in the masonry. Since the tubing material is flexible, as it expands it conforms to the contours of the hole and completely fills the circumference of the holes. Thus, the value of $A_{T}$ can be estimated by multiplying the length of the tubing material by the diameter of the hole and multiplying that value by the number of tube-jacks. The value of $A_{H}$ can be calculated by multiplying the diameter of each hole by the length of each hole and then summing those values. A diagram of these areas is shown in Figure 3. This cross-section assumes that all of the holes are in a straight joint.
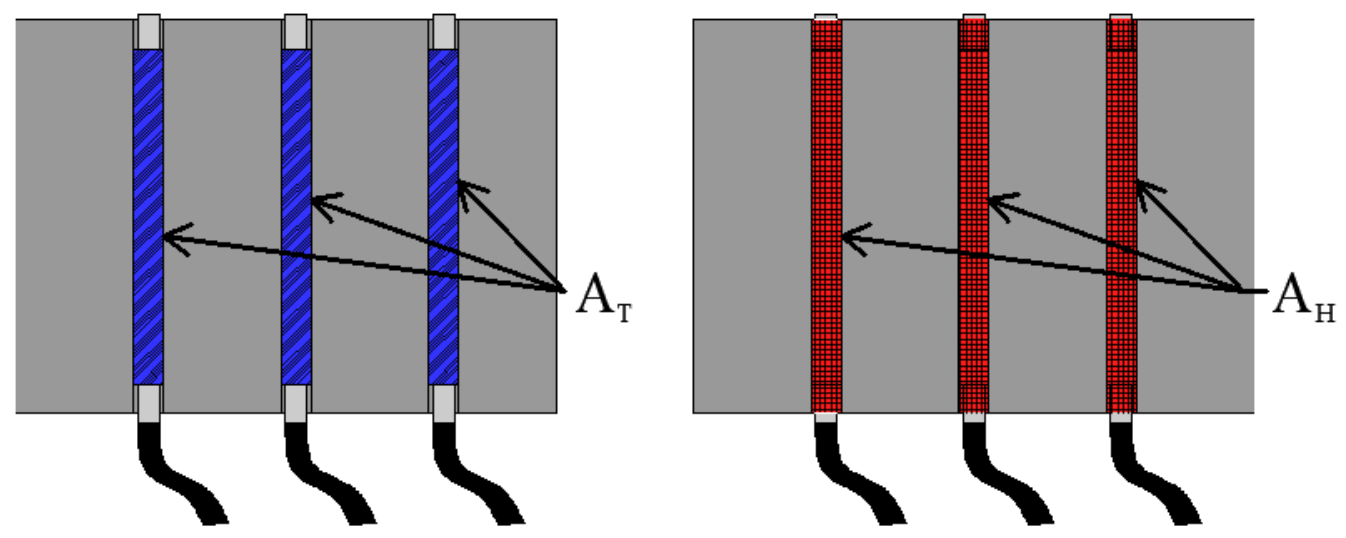

Fig. 3 Cross-section of masonry showing: the projected surface area of the pressurized tube-jacks on a plane through the centroid of the tube-jacks, $A_{T}$, and the cross-sectional area of the drilled holes, $A_{H}$ 


\section{MASONRY WALL CONSTRUCTION AND CHARACTERIZATION}

\subsection{MASONRY WALL CONSTRUCTION}

A large masonry wall was built in the Structural Lab of the University of Minho for the purpose of testing the tubejack test method. The single leaf wall was made with granite blocks with dimensions of $20 \mathrm{~cm}$ by $40 \mathrm{~cm}$ by $20 \mathrm{~cm}$ and a low strength cement-lime mortar in a regular masonry typology. The design and construction of the wall are shown in Figure 4. Vertical and horizontal mortar joints were $3 \mathrm{~cm}$ wide in order to insert the tube-jacks of $20 \mathrm{~mm}$ diameter completely within the mortar. Figure $4 \mathrm{a}$ also shows how the wall was loaded, a $2 \mathrm{~m}$ long steel profile with hydraulic jacks, which can apply pressure from the reaction floor above. A rubber mat was used between the top of the wall and the steel profile to provide uniform contact between the two elements. The wall was allowed to cure in general laboratory conditions for 50 days before any testing was performed.

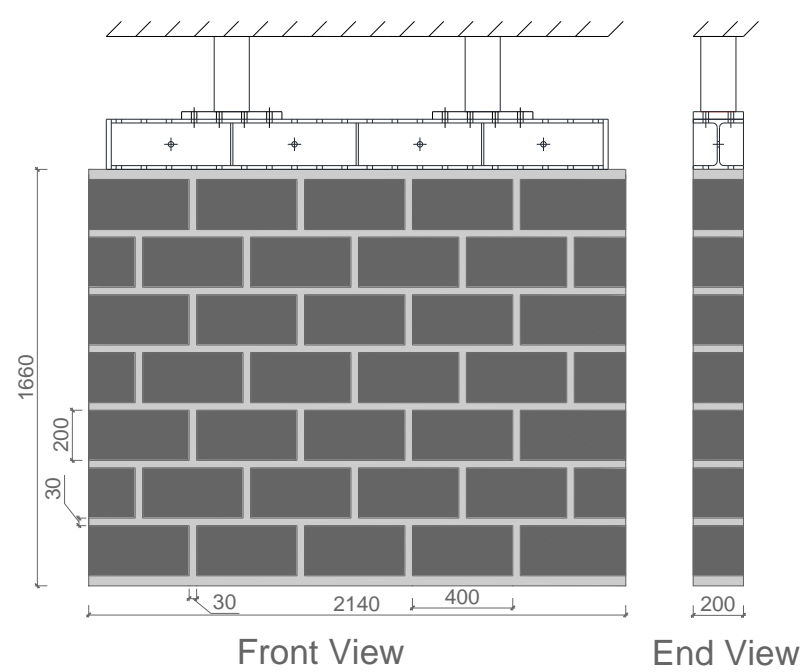

(a)

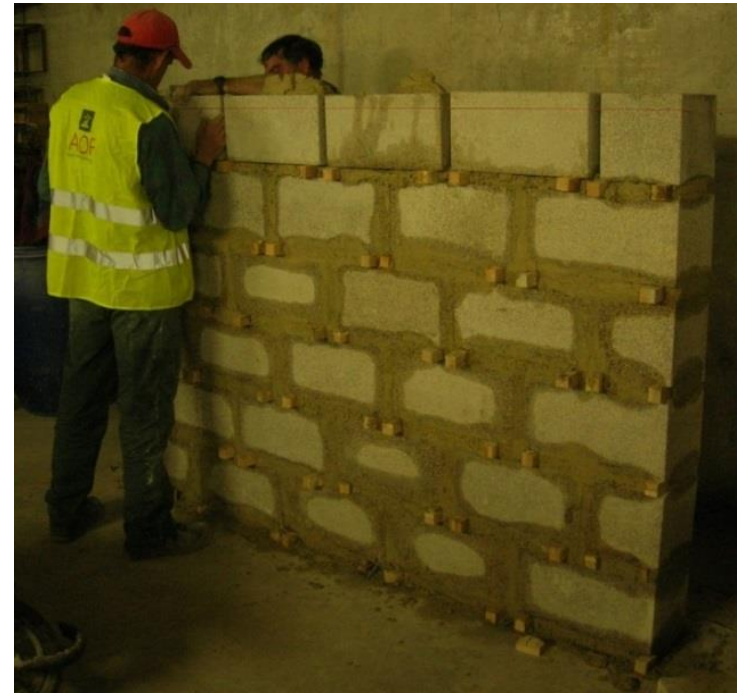

(b)

Fig. 4 Regular masonry wall: (a) design, dimensions [mm] and loading with hydraulic jacks; and (b) construction in the laboratory by a local construction company

\subsection{MATERIAL CHARACTERIZATION}

Young's modulus and compression tests were performed on three small masonry wallets built at the same time as the large masonry wall and with the same materials and typology. These tests were based on the European Standard [9] and were first presented elsewhere [10]. The first Young's modulus test was performed to a very low maximum stress level because the compressive strength of the masonry was assumed to be low. Compressive strength test of 
this specimen revealed that the compressive strength of the masonry was much higher than anticipated and was in fact higher than could be tested with the testing equipment. The results from the Young's modulus test and compressive test of the second specimen were inaccurate due to an eccentricity in the applied load that was discovered following those completed tests. Thus, mechanical properties are only presented from the successful testing of the final specimen (Fig. 5a). The reloading Young's modulus was approximately $2.5 \mathrm{GPa}$. The Poisson ratio was calculated to be 0.218 , and the compressive strength was greater than $4.167 \mathrm{MPa}$.

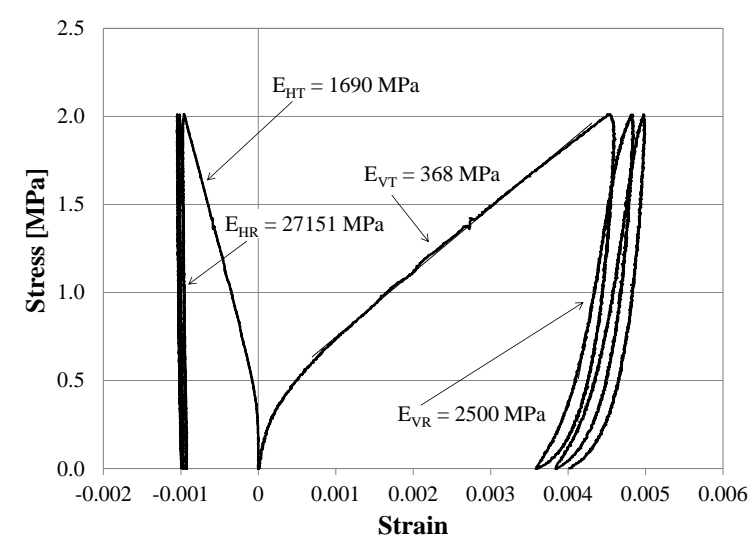

(a)

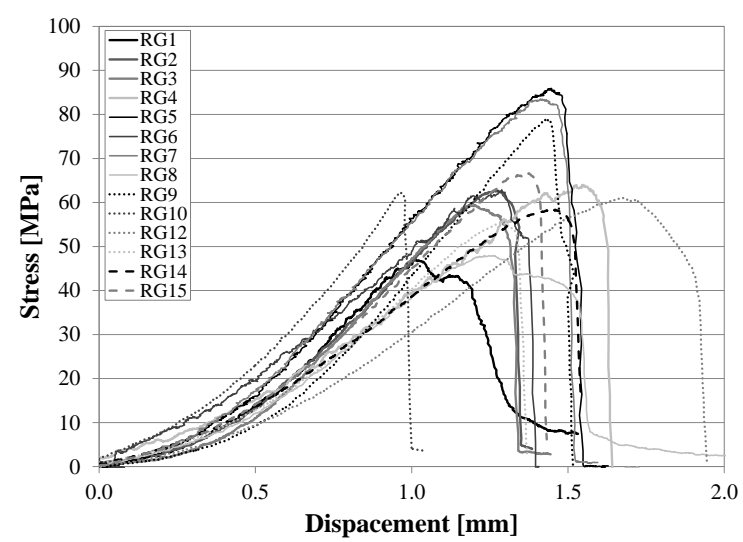

(b)

Fig. 5 Results of the mechanical characterization of the materials: (a) masonry wallet Young's modulus test; and (b) granite cylinders compression tests

The mechanical characterization of the constituent materials of the regular masonry wall was also carried out and initially presented elsewhere [10]. Updated results for the granite compression tests are presented here (Fig. 5b). The Young's modulus of the granite cylindrical test specimens was found to be $30 \mathrm{GPa}$ with a standard deviation of 4.71 GPa $(\mathrm{COV}=15.7 \%)$. The compressive strength of the granite was on average $65.04 \mathrm{MPa}$ with a standard deviation of 12.01 MPa $(\mathrm{COV}=18.5 \%)$. Mortar cylinders were also tested in compression. The Young's modulus of the mortar was $281 \mathrm{MPa}$ with a standard deviation of 57.6 MPa $(\mathrm{COV}=20.5 \%)$. The compressive strength of the mortar was $0.32 \mathrm{MPa}$ with a standard deviation of $0.048 \mathrm{MPa}(\mathrm{COV}=14.9 \%)$.

\section{SINGLE TUBE-JACK TESTS}

Single tube-jack tests were performed in some of the horizontal mortar joints of the regular granite masonry wall. These were the first single tube-jack tests to be performed using the water pressure system as described previously in this paper (Figure 1). To prevent holes from previous tests from influencing subsequent tests, the holes were filled with mortar, which was allowed to harden, before subsequent tests were performed. 
Rubber tubing with an inner radius of $6.34 \mathrm{~mm}$ and a thickness of $0.82 \mathrm{~mm}$ was used as the tubing material for the tube-jacks. Five rubber specimens were tested in tension to determine the elastic modulus following ASTM standard D412-98a [11]. The average elastic modulus of the rubber was 2.32 MPa with a standard deviation of $0.044 \mathrm{MPa}$ $(\mathrm{COV}=1.91 \%)$. The rubber tensile testing and results of the fifth specimen are shown in Figure 6. A Poisson ratio of 0.499 was assumed for the rubber. A steel bolt, $6 \mathrm{~mm}$ in diameter, was included in the center of each tube-jack to keep the tubing from expanding longitudinally and to aid in inserting the tube-jacks into the holes. Tubular knitted fibrous structures were placed over the length of the tube to confine the tubing and prevent them from bursting at low pressures. Further information about the tubular knitted fibrous structures can be found elsewhere [3]. The tubing and tubular knitted fibrous structures were clamped at the ends with metal end fittings. One of the tube-jacks is shown in Figure 1a.

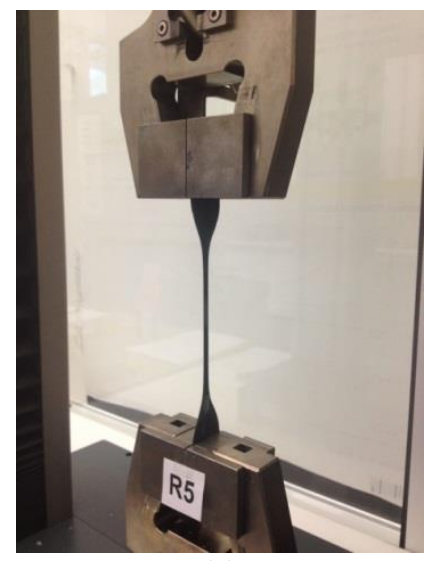

(a)

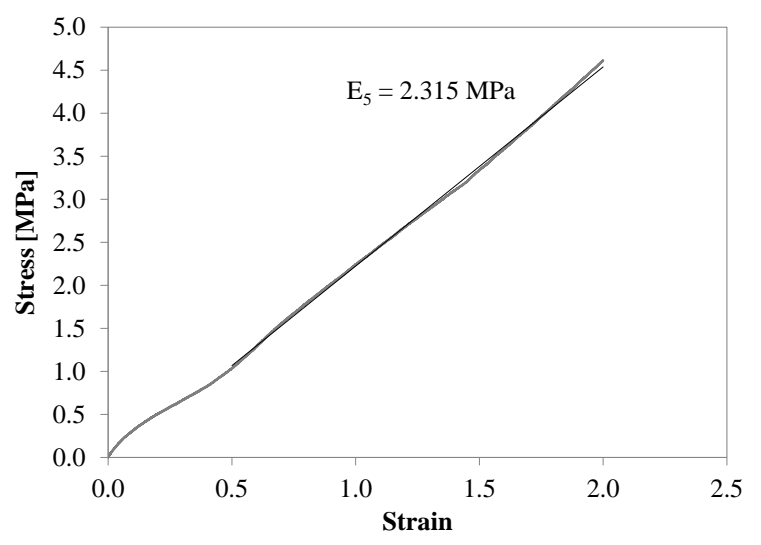

(b)

Fig. 6 Tensile testing of the tubing rubber: (a) photo during testing of specimen R5; and (b) specimen R5 stress versus strain results

In all of the single tube-jack tests, the wall was loaded using the two hydraulic jacks, as shown in Figure $4 b$, the day before the test, in order for the wall to adjust to the loading. Before, during, and after each test, the load on the wall was checked and maintained. For each test the stress state in the wall at the joint being tested was calculated based on the pressure in the hydraulic jacks loading the wall and the weight of the masonry and equipment above the joint.

The set-up for each of the single tube-jack tests was the same, except where noted in the following sections. The holes for the tube-jacks were spaced approximately $7.5 \mathrm{~cm}$ from center to center. Eight LVDTs were used, four on the front of the wall and four on the back. The ranges of the LVDTs were $\pm 2.5 \mathrm{~mm}$ for LVDTs $1-5, \pm 10 \mathrm{~mm}$ for LVDTs 6-7 and $\pm 7.5 \mathrm{~mm}$ for LVDT 8. All of the LVDTs had a precision level of at least $99.5 \%$. The placements of 
the LVDTs were between the 2nd and 3rd holes, between the 5th and the 6th holes, between the 7th and the 8th holes, and between the 10th and 11th holes, on both sides of the wall. They were labelled LVDT 1 through 4 , respectively, on the front of the wall and LVDT 5 through 8, respectively, on the back of the wall (see Figure 7).

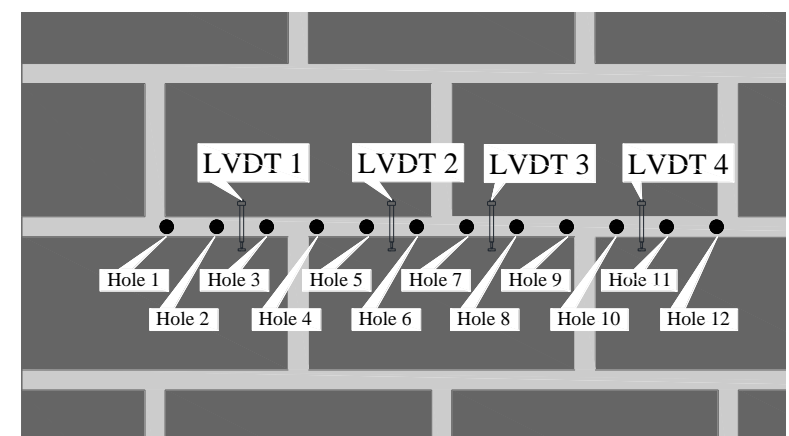

(a)

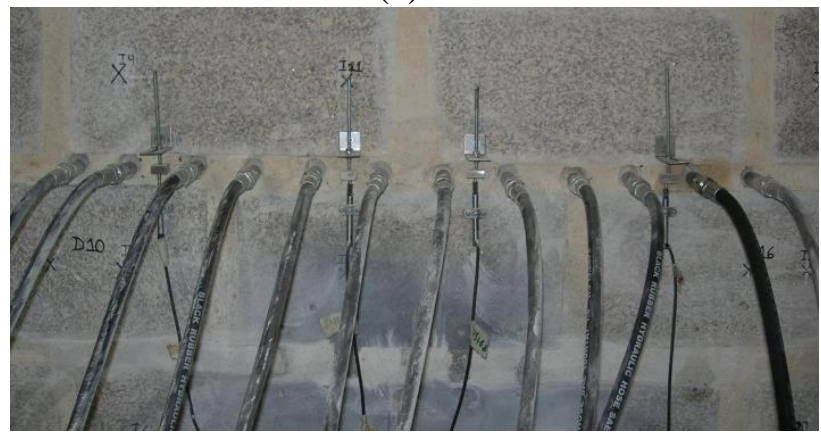

(c)

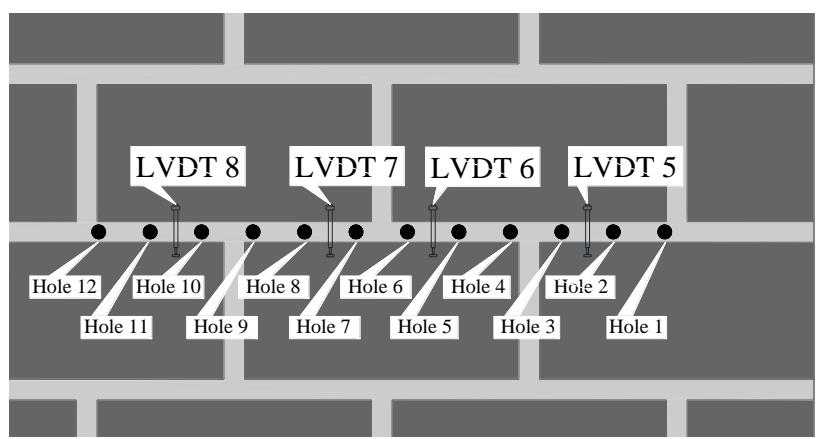

(b)

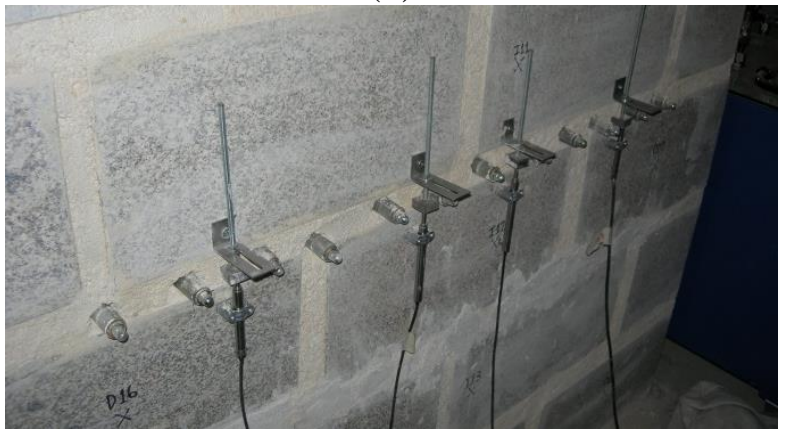

(d)

Fig. 7 Holes and LVDT positions for the single tube-jack tests: (a) front of the wall; (b) back of the wall; (c) tubejacks inserted in the front of the wall; and (d) tube-jack ends sticking out the back of the wall

During the test, the holes for the tube-jacks were drilled starting from the center holes and working toward the outer holes. The displacements of the LVDTs were recorded both during the drilling process and after the drilling was completed. The tube-jacks were not inserted into the holes or pressurized until the movement of the LVDTs was nearly zero.

Following all of the tests on the regular masonry wall, the holes drilled for the test in the fifth horizontal joint were injected with foam. The wall was dismantled and the foam pieces extracted carefully. The diameter of each foam piece was measured every five centimeters. The results were averaged and used as the average diameter of the tubejack holes. The average diameter, $26 \mathrm{~mm}$, is assumed to be the outer diameter of the deformed tube when the tubejack is inflated to the size of the hole and this value is used in the calculation of the pressure applied to the masonry by the tube-jacks, $p_{m}$. 
The area correction factor for the single tube-jack tests was calculated following the tests. Since the tube-jacks expand to fill the holes, the area correction factor can be simplified to the ratio of the average contact length of the tubing material to the wall thickness, $20.0 \mathrm{~cm}$. The average contact length of the tubing material was measured to be $16.5 \mathrm{~cm}$. Thus, the area correction factor, $k_{A}$, for the single tube-jack tests was 0.825 . The area correction factor was multiplied by the pressure applied to the masonry by the tube-jacks, $p_{m}$, to produce the applied pressure, $p_{\text {Applied, }}$, which is shown in the graphs in the following sections. At the point when the average LVDT displacements are restored to zero, as shown in the graphs in the following sections, the applied pressure value is an estimate of the stress state in the masonry.

\subsection{SINGLE TUBE-JACK TEST IN THE 3RD HORIZONTAL JOINT}

The first complete tube-jack test performed on the regular granite masonry wall with the new water pressure system was conducted in the $3^{\text {rd }}$ horizontal mortar joint up from the base of the wall, where the stress level was calculated to be approximately $0.23 \mathrm{MPa}$.

The drilling results of the test are presented in Figure 8. It can be seen in Figure 8a that while most of the movement of the masonry is complete shortly after the holes had been drilled, movement was observed for over one hour as the wall stabilized. Figure $8 \mathrm{~b}$ shows the average relative displacement of all of the LVDTs, approximately $8.5 \mu \mathrm{m}$, and the average of the front and back LVDTs separately. The difference in displacements between the front and back LVDTs show that the front of the wall had a much more negative relative displacement than the back of the wall. It was discovered that the steel profile on top of the wall was out of alignment and causing a slight eccentricity of the loading resulting in a higher stress level on the front of the wall than on the back. Following the test, the alignment of the steel profile was corrected by moving the steel profile slightly towards the back of the wall. 


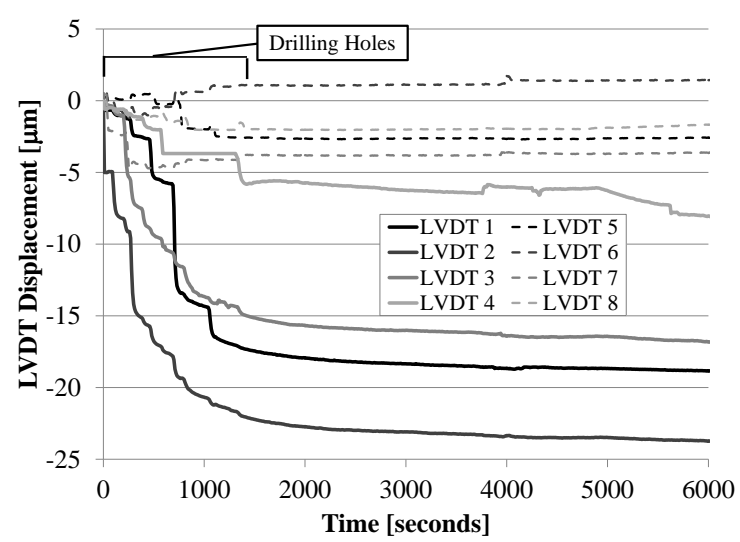

(a)

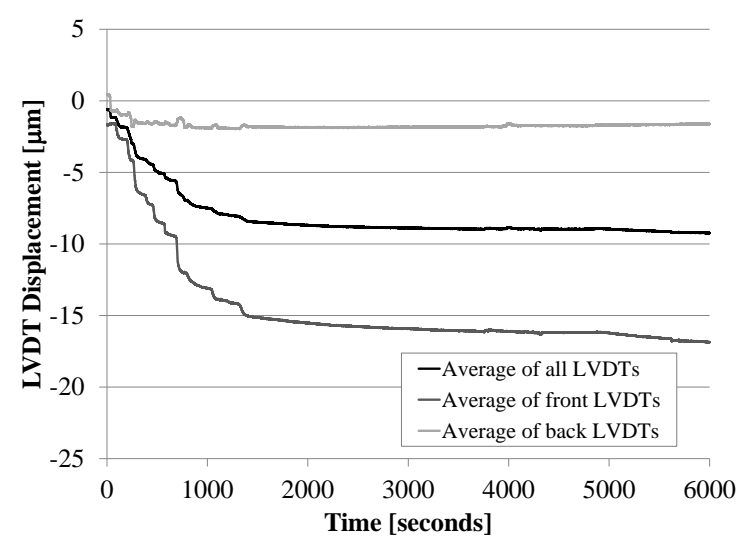

(b)

Fig. 8 Hole drilling results for the 3rd horizontal joint: (a) individual LVDT displacements; and (b) average LVDT displacements

Once the wall had stabilized, the tube-jacks were inserted and three pressurizations performed (see Figure 9a). After the first pressurization, the wall was allowed to stabilize again before the second pressurization. The lower curve of each pressurization cycle is the loading portion and the upper curve is the release of pressure. The applied pressure value when the average relative displacement has reached zero on the loading curve estimates the state of stress in the masonry. Pressurizations 2 and 3 come closest to the calculated stress level and estimate it to be $0.26 \mathrm{MPa}$, with an error of $13 \%$.

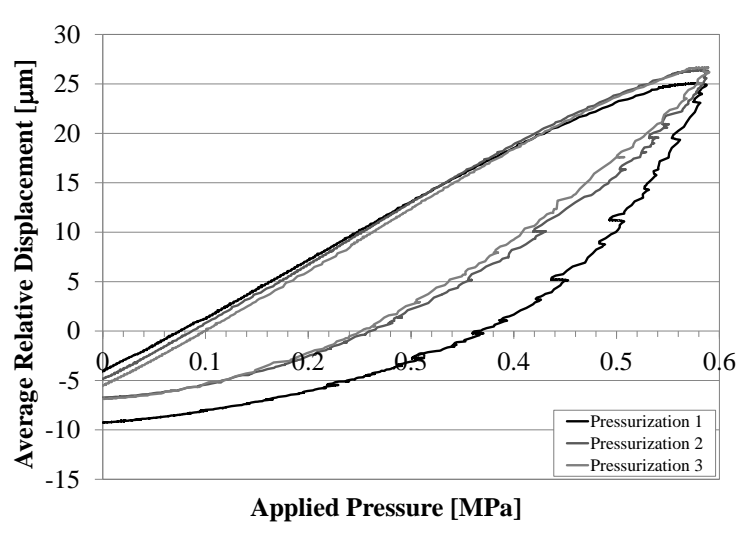

(a)

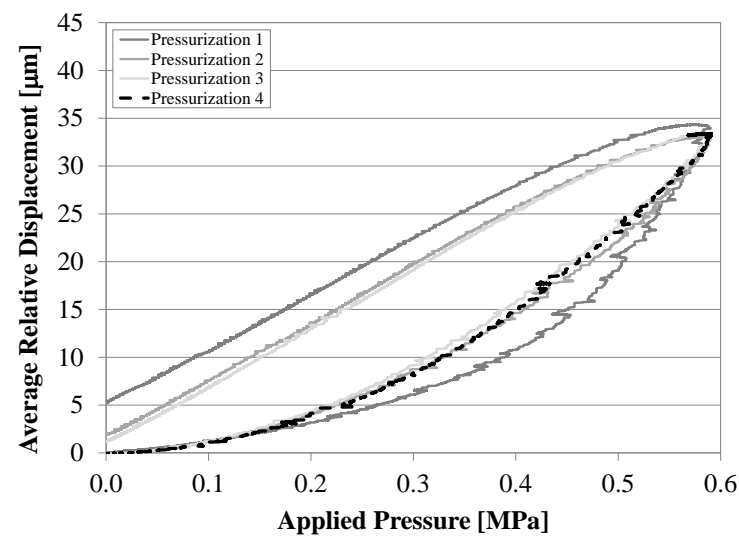

(b)

Fig. 9 Tube-jack test results for the $3^{\text {rd }}$ horizontal mortar joint (a) first test; and (b) subsequent pressurization in comparison with the first test with initial LVDT displacements zeroed for each pressurization

Three days after the single tube-jack test in the 3rd horizontal joint, a pressurization test was performed in the same joint and with the same set-up as the previous test. Since the holes were not drilled at the same time as the test and the wall had been allowed to settle during the previous three days, this was not considered a complete single tubejack test. The tube-jacks were pressurized to an internal water pressure of approximately $0.8 \mathrm{MPa}$. At this pressure, 
tube-jack \#2 burst, reducing the pressure in the jacks to zero and ending the test. The results, labelled Pressurization 4, are shown in Figure 9b in comparison with the pressurizations from the first test. After the initial pressurization all subsequent pressurizations followed approximately the same pressure-displacement curve.

\subsection{SINGLE TUBE-JACK TEST IN THE 4TH HORIZONTAL JOINT}

A single tube-jack test was also performed in the 4th horizontal joint up from the base of the regular masonry wall. The stress level at the 4th horizontal joint was calculated to be $0.224 \mathrm{MPa}$.

The results of the hole drilling are presented in Figure 10. In the graph of the individual LVDT displacements, Figure 10a, it can be seen that LVDTs in the same location but on opposite sides of the wall have similar downward displacements. For example, LVDTs 2 and 6 both have a downward displacement of approximately 5 microns after the drilling is complete. Similarly, LVDTs 3 and 7 have a downward displacement of approximately $6 \mu \mathrm{m}$. The time required for the wall to stabilize was much less than in the test performed in the $3^{\text {rd }}$ joint. The graph of the average LVDT displacements, Figure 10b, shows that the movement of the front and the back of the wall is similar and that the eccentricity of the loading on the top of the wall had been corrected. The average downward displacement of the LVDTs resulting from drilling the holes was approximately $6.5 \mu \mathrm{m}$.

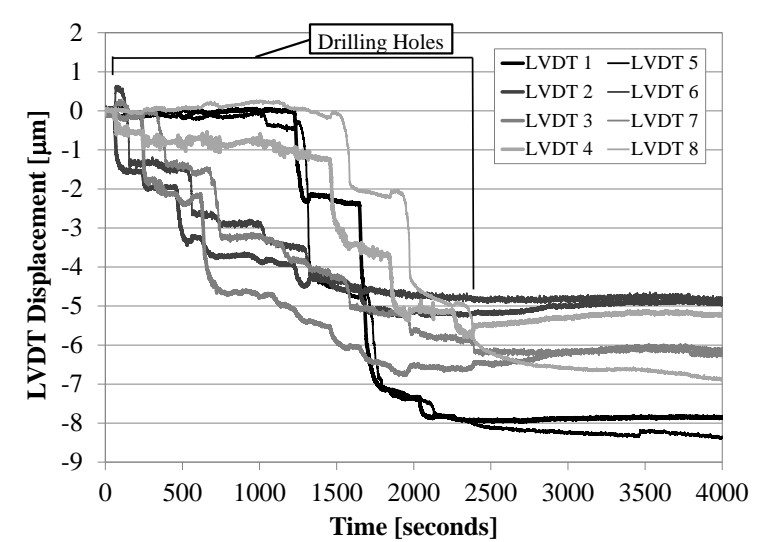

(a)

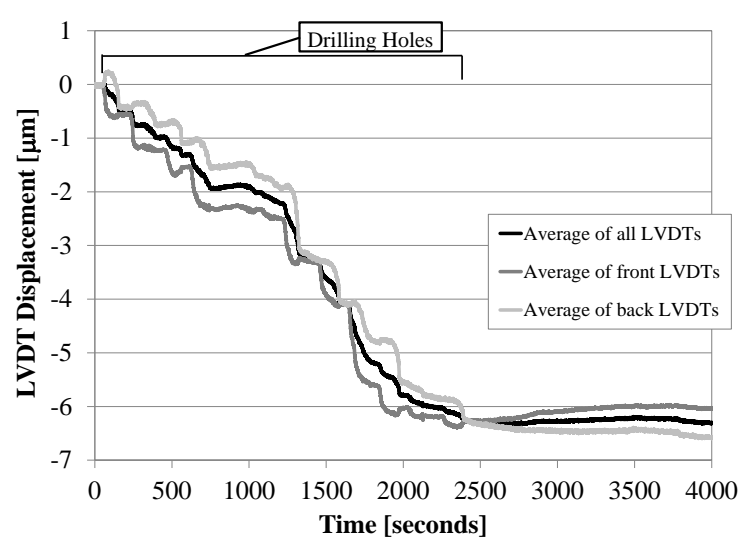

(b)

Fig. 10 Hole drilling results for the $4^{\text {th }}$ horizontal joint: (a) individual LVDT displacements; and (b) average LVDT displacements

After the movement of the LVDTs had reduced to nearly zero, the tube-jacks were inserted into the holes and pressurized. Two pressurization cycles were conducted; the first one to $0.35 \mathrm{MPa}$ and the second to $0.42 \mathrm{MPa}$ in applied pressure. As in the tube-jack test performed in the $3^{\text {rd }}$ horizontal joint, the pressurizations performed in the 
$4^{\text {th }}$ horizontal joint show a consistent loading curve (see Figure 11). The average LVDT relative displacements are restored to zero at an applied pressure of $0.34 \mathrm{MPa}$ (error equal to 52\%). Unfortunately this estimated stress does not correspond to the calculated stress level at this joint, $0.224 \mathrm{MPa}$.

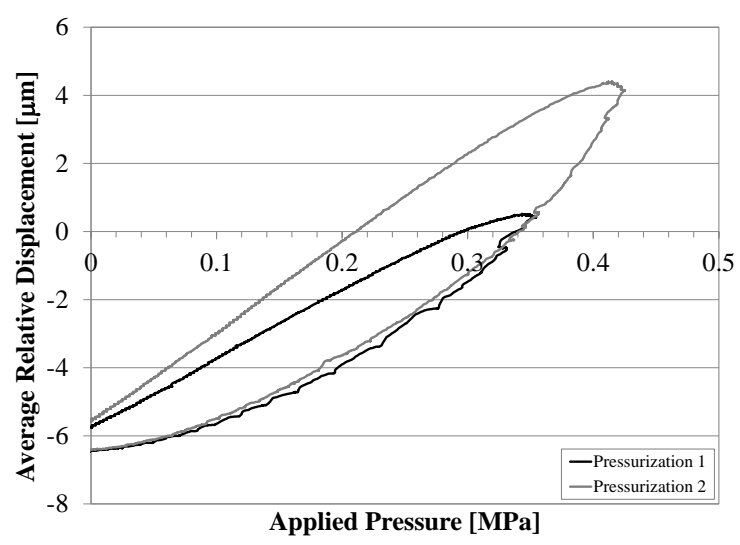

(a)

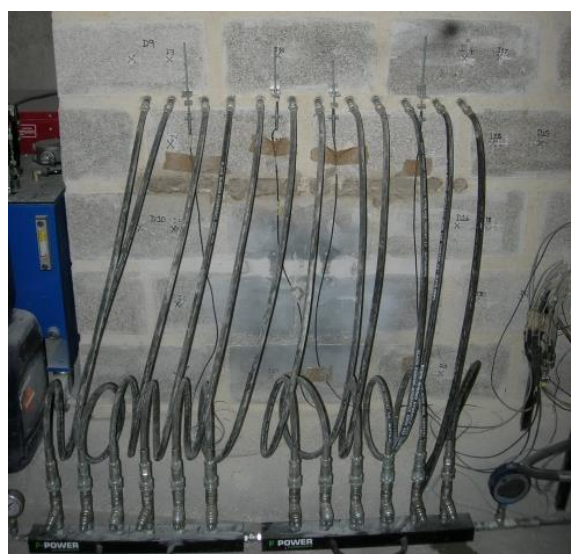

(b)

Fig. 11 Tube-jack test results for the $4^{\text {th }}$ horizontal mortar joint: (a) calculated pressure versus average relative displacement results; and (b) photo of the tube-jack pressurization

\subsection{SINGLE TUBE-JACK TEST IN THE 5TH HORIZONTAL JOINT}

The final tube-jack test performed on the regular masonry wall was performed in the 5th horizontal mortar joint from the base of the wall. This test was different from the previous tests; it was performed after flat-jack tests had been performed at the other end of the wall and the load on the wall was doubled, producing an estimated stress level of approximately $0.42 \mathrm{MPa}$ at the joint. Similar to the first tube-jack test in the $3^{\text {rd }}$ horizontal joint, the front LVDTs showed much more negative relative displacements than the back LVDTs, see Figure 12a, indicating a higher stress level on the front of the wall than on the back of the wall. Even though the flat-jack tests were performed at the other end of the wall, it is likely that the creation of the flat-jack slots in the wall resulted in a weakening of the front of the wall, since the slots were only cut half way through the thickness of the wall. This likely led to an eccentricity in the loading for the tube-jack test performed in the fifth horizontal mortar joint. The average relative displacement of the LVDTs, due to the hole drilling in the fifth horizontal joint, was approximately $-54 \mu \mathrm{m}$, over eight times the average relative displacement of the masonry when the stress in the wall was half as much. During the time allowed for the wall to adjust to the holes, the displacement decreased a further $6 \mu \mathrm{m}$. 


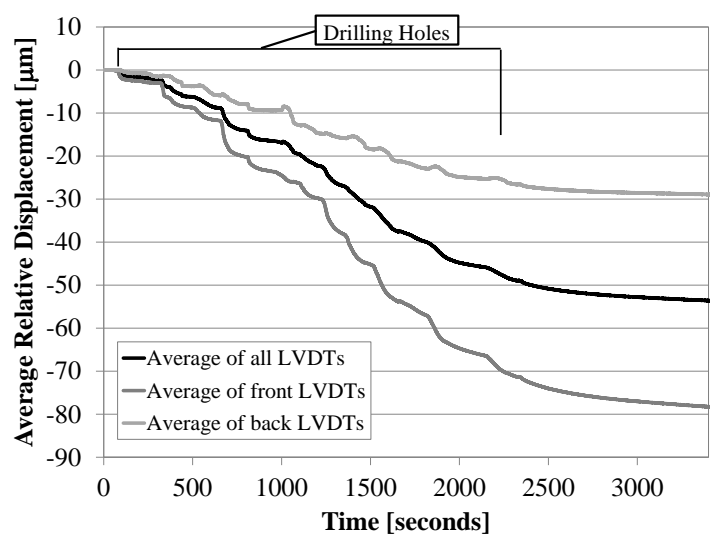

(a)

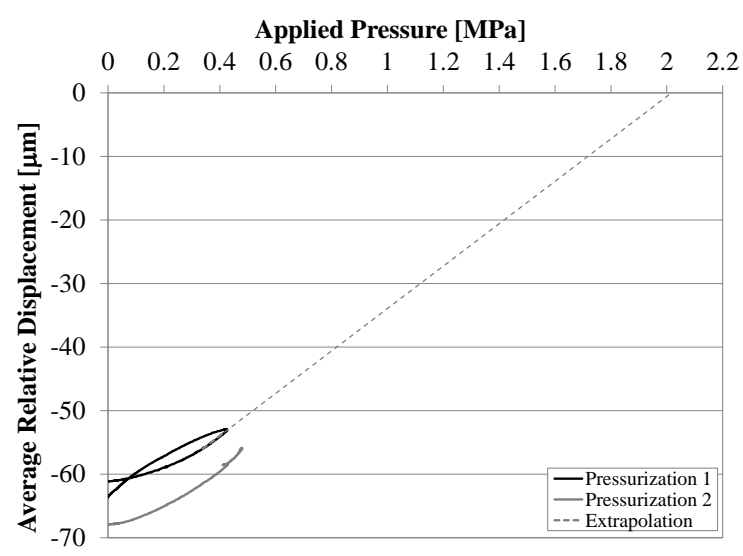

(b)

Fig. 12 Average LVDT displacement results for the $5^{\text {th }}$ horizontal joint: (a) during hole drilling; and (b) versus applied pressure during pressurizations

After the movement of the LVDTs had reduced to nearly zero, the tube-jacks were inserted into the holes and pressurized. The tube-jacks were pressurized to applied pressure values of $0.4 \mathrm{MPa}$ in the first cycle and $0.5 \mathrm{MPa}$ in the second cycle. During the second pressurization cycle tube-jack \#3 burst. The results of the two pressurization cycles are shown in Figure 12b. The results show that average relative displacement of the LVDTs due to drilling the holes was not recovered during the first pressurization. At most only $12 \mu \mathrm{m}$ was recovered in each pressurization. When the pressure was released in the tube-jacks after each pressurization, the relative displacement continued to decrease as the wall continued to settle. Thus, during this test the wall was still establishing equilibrium.

\section{SINGLE FLAT-JACK TEST}

\subsection{TEST SETUP AND PROCEDURE}

A single flat-jack test was performed on the right side of the regular masonry wall to compare the flat-jack test with the tube-jack tests in the same masonry wall. Following the single tube-jack test in the fourth horizontal mortar joint, the single flat-jack test was performed in the 3rd horizontal mortar joint up from the base of the wall (see Figure 13a). The pressure in the jacks loading the wall was $2.82 \mathrm{MPa}$, which produced a stress level of $0.23 \mathrm{MPa}$ in the joint tested. A flat-jack with dimensions of $40 \mathrm{~cm}$ long and $10 \mathrm{~cm}$ deep and jack calibration factor, $k_{m}$, of 0.77 was used for the test. 


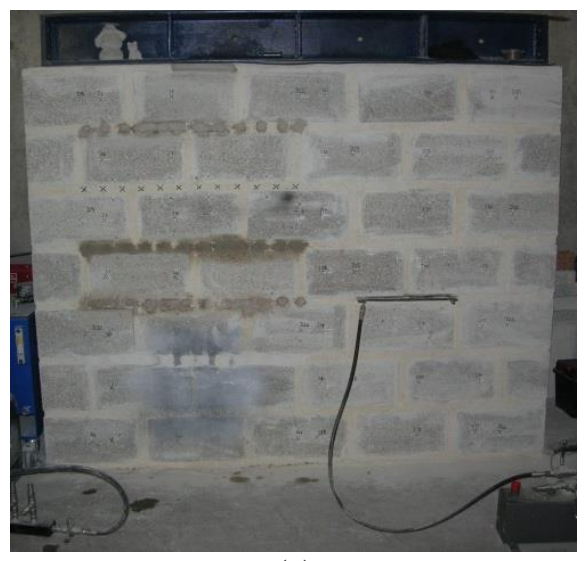

(a)

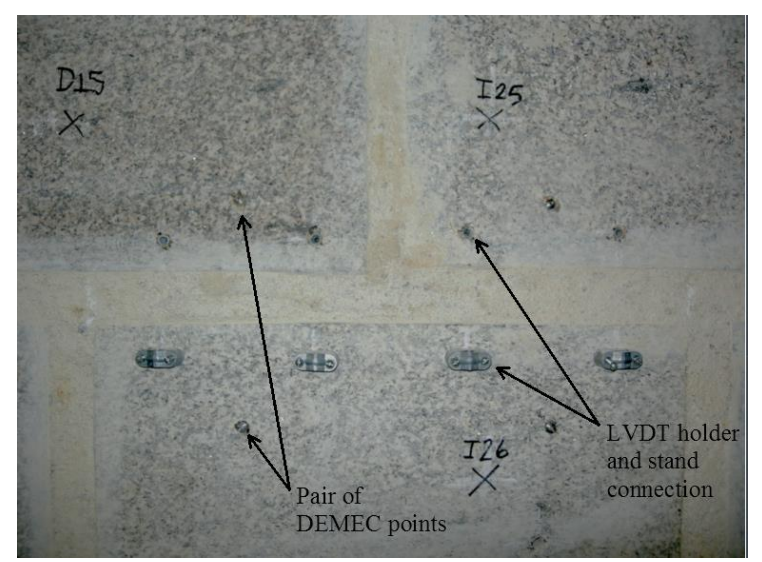

(b)

Fig. 13 Single flat-jack test setup: (a) flat-jack test position in regular masonry wall; and (b) attachment of LVDT holders and DEMEC points

In preparation for the single flat-jack test, holes were drilled to attach the LVDT holders and the measuring points for the demountable mechanical strain gage (DEMEC) were glued in place (Figure 13b). Four LVDT holders were positioned on either side of the wall, each $10 \mathrm{~cm}$ apart with the outer LVDTs $5 \mathrm{~cm}$ from the end of the slot. The LVDTs measured over a vertical distance of $8 \mathrm{~cm}$. Two sets of DEMEC points were placed on each side of the wall, half way between the LVDT lines.

The vertical measurements for the DEMEC point pairs were taken before the slot was made, after the slot was made, and throughout the test using the DEMEC shown in Figure 14a. The slot was made using the saw in Figure 14b.

Since the saw was unable to make a clean and even slot, additional chiseling was necessary to complete the slot (Figure 14c).

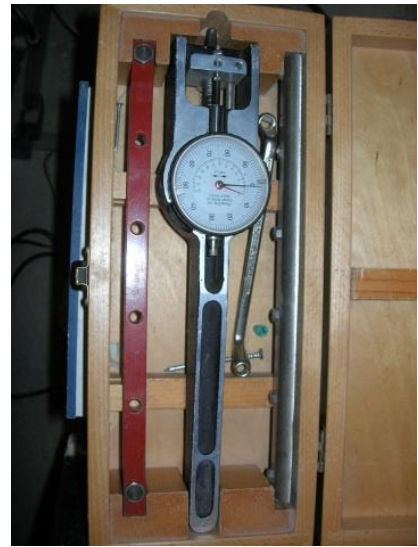

(a)

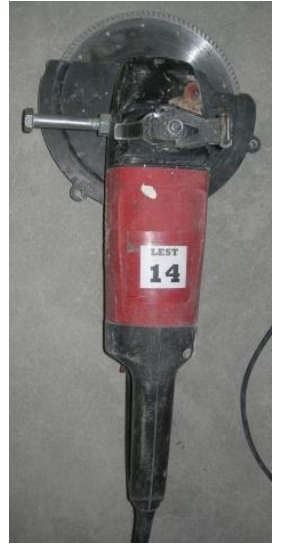

(b)

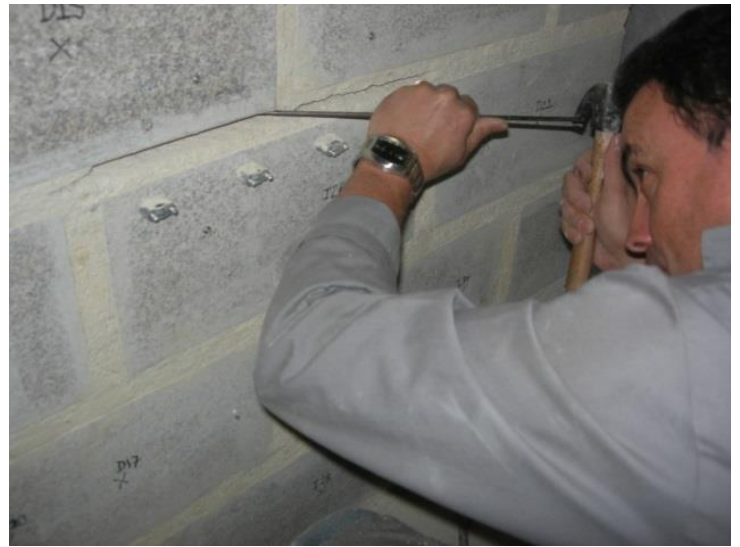

(c)

Fig. 14 Testing equipment and slot preparation: (a) DEMEC; (b) circular hand saw; and (c) additional chiselling necessary to complete the slot 
When the slot was prepared, the flat-jack was inserted into the slot. Several shims needed to be inserted above and below the slot to fill in the extra space in the slot around the flat-jack. After the flat-jack was in place, the LVDTs were attached (Figure 15a). The final setup, including the oil hand pump and the data acquisition system, is shown in Figure 15b.

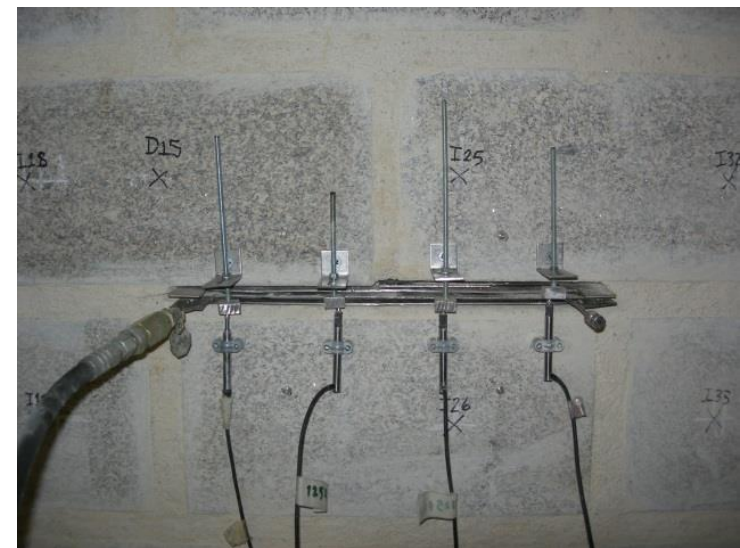

(a)

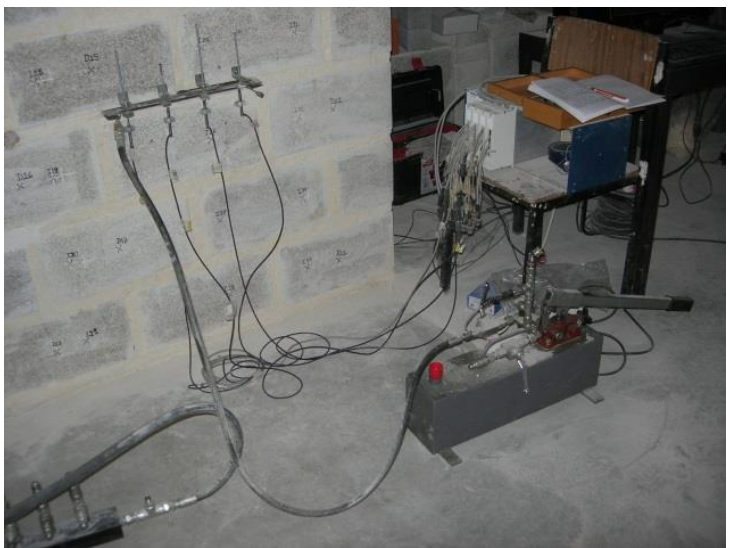

(b)

Fig. 15 Final single flat-jack test setup: (a) flat-jack inserted and LVDTs attached; and (b) complete setup including oil hand pump and data acquisition system

\subsection{RESULTS}

The results of the DEMEC measurements are shown in Figure 16a. Measurements were taken at five points in time. The time points are described in Figure 16b. At each time point, three measurements were made for each of the lines. While the DEMEC device could read measurements as small as $0.002 \mathrm{~mm}$, the measurements taken were variable. The standard deviation for each set of three measurements was on average $0.033 \mathrm{~mm}$. As shown in the results, after the slot was opened there was a downward movement of the wall on the back of the wall (Line 3 and 4), very slight downward movement on the front left side of the slot (Line 1) and an upward movement on the front right side of the slot (Line 2). The upward movement on the right side of the slot and greater downward movement on the back of the wall could be due to movement of the individual units, since the slot is only the length of one unit. The average downward movement of the wall, as measured by the DEMEC, was $0.18 \mathrm{~mm}$. The stabilization of the wall after the removal of the mortar in the slot is seen by comparing time points 2 and 3 . 


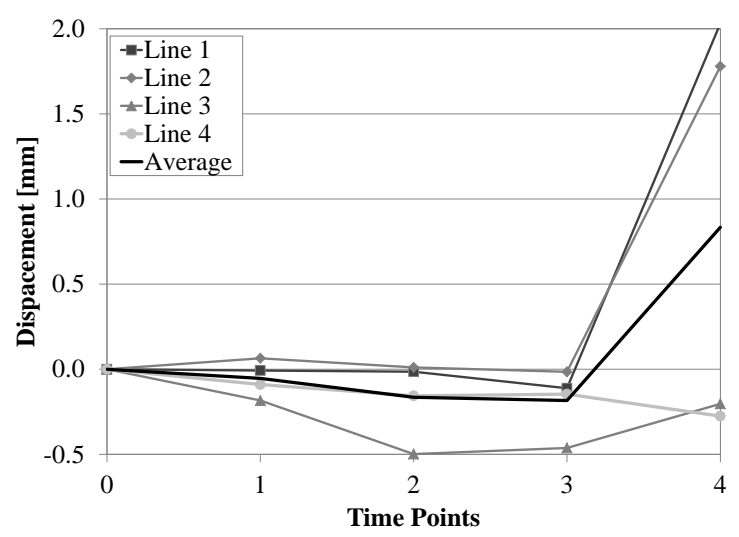

(a)
Time Point

0

1

2

3

4

Fig. 16 DEMEC results: (a) displacement at various time points during the test; and (b) time point descriptions

Since the calculation of the vertical displacement of the wall from the DEMEC point measurements was performed following the completion of the test, this information was not available during the pressurization of the flat-jack. Before starting the pressurization cycles, the flat-jack was pressurized to $0.8 \mathrm{MPa}$ of oil pressure to seat the jack in the slot. Four pressurization cycles were performed with the single flat-jack. The first cycle was to $2.8 \mathrm{MPa}$ and each subsequent cycle was to 2.0 MPa in oil pressure (Figure 17a). Note that the small dips in the pressure were disruptions in the electrical power supply for the oil pressure gage and were not actual dips in the pressure.

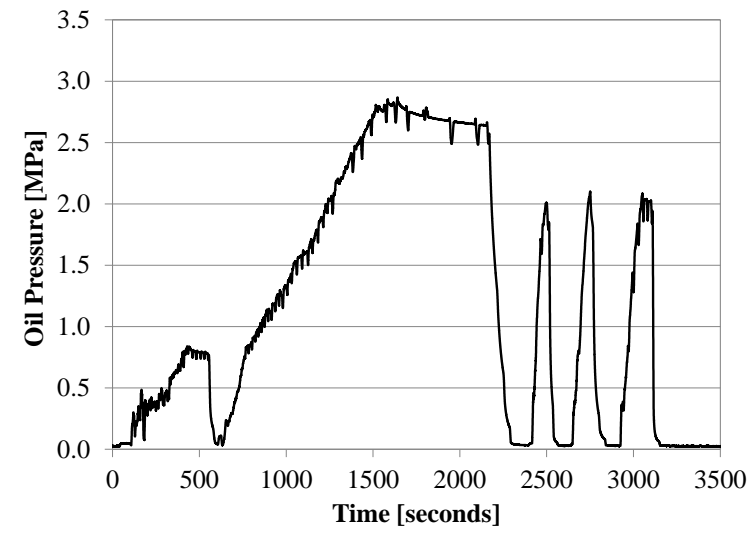

(a)

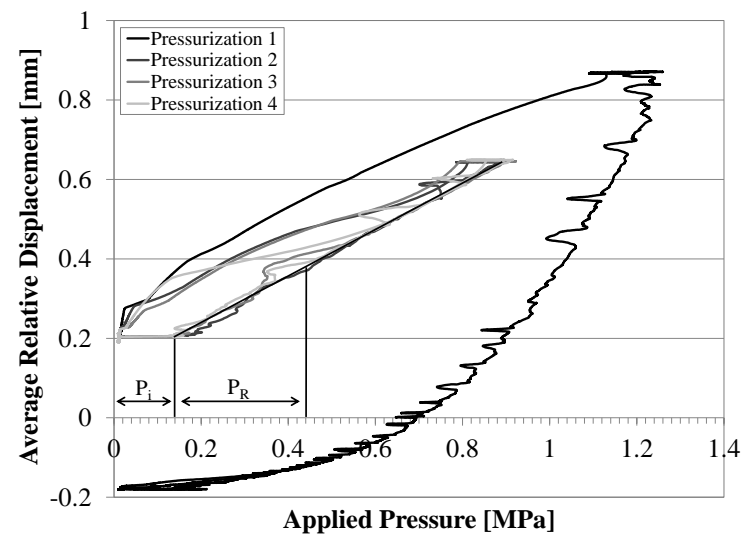

(b)

Fig. 17 Single flat-jack test results: (a) oil pressure over the length of the test; and (b) average LVDT relative displacement versus applied pressure

In order to determine the stress state in the wall using the flat-jack test data, several adjustments need to be made to the data. The initial values of the LVDTs were set to the average relative displacement caused by opening the slot and found using the DEMEC measurements, $-0.18 \mathrm{~mm}$. The area correction factor, $k_{a}$, was calculated to be $0.57 \mathrm{by}$ dividing the surface area of the jack by the measured surface area of the slot. The area correction factor was 
combined with the jack calibration factor to obtain a total correction factor, 0.439 . This was applied to the oil pressure data to obtain the applied pressure. The applied pressure versus the average LVDT relative displacement results (Figure 17b) show that the pressure required to return the average relative displacement to zero in the first loading is approximately $0.7 \mathrm{MPa}$. The curvature in the first loading cycle is likely due to the jack and masonry adjusting to the loading. The $2^{\text {nd }}$ through $4^{\text {th }}$ cycles show the linear elastic behavior of the masonry. The authors believe that the thickness of the joints and slot resulted in an initial inflation pressure, $P_{i}$, before the flat-jack applied pressure to the masonry in each cycle. Given the relative displacement to be restored is $-0.18 \mathrm{~mm}$, the restoring pressure, $P_{R}$, and estimate of the state of stress is $0.3 \mathrm{MPa}$. This result is much higher than the assumed stress level in the masonry, $0.23 \mathrm{MPa}$, and has an error of $30.4 \%$. The difference in values could be due to error in the DEMEC point measurements. It could also be that the flat-jack is not measuring the stress in the masonry because it is only the length of one granite unit and only half the width. Finally, the error could be due to the high pressure applied in the first cycle of the test, which caused permanent displacements.

\section{CONCLUSIONS AND FUTURE WORK}

In this paper the first single tube-jack tests performed in a regular masonry wall in a laboratory setting have been presented. Background information about the development of the tube-jack test method at the University of Minho, the tube-jack system and theory, and the characterization of the materials and masonry used, were given as a basis for these tests.

The first tube-jack test in the $3^{\text {rd }}$ horizontal masonry joint up from the base of the regular masonry wall showed that the tube-jack system was able to successfully restore the relative displacement of the wall from the drilling of the line of holes. Subsequent pressurizations showed that the pressure versus displacement curves were similar for each pressurization and that the test was repeatable even after some time had elapsed.

For the second tube-jack test in the $4^{\text {th }}$ horizontal masonry joint, the loading on the wall was adjusted to correct for some eccentricity that was noticed in the first test. By comparing the average displacements of the LVDTs on both sides of the wall during the drilling of the holes for this test, it could be confirmed that the eccentricity in the loading had been corrected. The first pressurizations using the rubber tube-jacks again confirmed that the test was 
repeatable. The pressure level required to return the displacements to zero in this test was $0.34 \mathrm{MPa}$, much higher than the calculated stress level. Further research must be done to determine the reason for the errors in these results.

The final tube-jack test was performed following the flat-jack test. The load on the regular masonry wall was doubled. The result of drilling the holes in the $5^{\text {th }}$ horizontal mortar joint was a large negative relative displacement. Even after the wall appeared to have stabilized after the drilling, continuous movement of the wall during the pressurization cycles suggests that the wall was still establishing equilibrium throughout the test. It is likely that the previous flat-jack test had weakened the front of the wall, resulting in an eccentricity in the loading. The tube-jacks were not able to recover the large negative relative displacements in this test. Further improvement to the tube-jacks will be necessary in order for them to be successful when higher stress levels are present in the masonry.

Finally, a traditional flat-jack test was performed in the same regular granite masonry wall. The stress level in the wall at the time of this test was the same as for the tube-jack tests performed in the $3^{\text {rd }}$ and $4^{\text {th }}$ horizontal mortar joints. This test demonstrated some of the difficulties of performing a flat-jack test in this type of masonry. The slot was difficult to prepare with traditional methods: saw cutting produced large amounts of dust, the slot was uneven, and it was difficult to obtain the correct depth. A reciprocating saw with vacuum attachments could solve these issues for future tests. The tube-jack test, on the other hand, did not require any additional equipment to create straight holes without dust. The large thickness of the joints in this masonry likely led to the error in the first loading cycle and an initial inflation pressure in each cycle before pressure was applied to the masonry. The variability of the DEMEC measurements was large and this is a likely source of error in the results. Since the DEMEC device must be removed during slot preparation, there is no way of recording the movement of the masonry during this part of the test. In contrast, the placement of LVDTs between the holes in the tube-jack test allows the movement of the wall to be recorded throughout the creation of the holes. The inflexibility of the flat-jack size meant that it was only pressurizing one quarter of each granite unit above. In addition, the DEMEC and LVDTs only measured between three units. Thus, the traditional flat-jack test method only tested two units and not the masonry as a whole, leading to the inaccuracy of the stress state results.

In conclusion, these initial tube-jack tests have shown to be a promising method for determining the stress state in large unit regular masonry at low stress levels in the future. The tube-jack test method was able to test a larger area of the masonry than the traditional flat-jack tests with fewer issues in creating the holes than the slot and in 
measuring the displacements. This led to tube-jack test results that were closer to the actual stress state in the masonry than the flat-jack test results. Further testing is required to determine the causes for error in the tube-jack test results and to determine if the tube-jack test method can be successful in semi-irregular and irregular masonry walls. Finally, if the tube-jacks are to be used in masonry with higher stress levels, the tube-jacks must be improved so they are able to apply larger pressures to the masonry.

\section{REFERENCES}

[1] A. Anzani, L. Binda, A. Carpinteri, S. Invernizzi and G. Lacidogna, "A multilevel approach for the damage assessment of Historic masonry towers," Journal of Cultural Heritage, vol. 11, pp. 459-470, 2010.

[2] RILEM Recommendation MDT.D.4: In-situ stress tests based on the flat-jack, $2004 .$.

[3] L. F. Ramos, E. Manning, F. Fernandes, R. Fangueiro, M. Azenha, J. Cruz and C. Sousa, "Tube jack testing for irregular masonry walls: prototype development and testing," NDT\&E, vol. 58, no. September, pp. 24-35, 2013.

[4] L. Binda and C. Tiraboschi, "Flat-Jack Test as a Slightly Destructive Technique for the Diagnosis of Brick and Stone Masonry Structures," Int. J. for Restoration of Buildings and Monuments, pp. 449-472, 1999.

[5] Standard Test Method for In Situ Compressive Stress within Solid Unit Masonry, Estimated Using Flat-jack Measurements, ASTM Standard C 1196-04, 2004..

[6] L. F. Ramos and Z. Sharafi, "Tube-jack Testing for Irregular Masonry Walls: First Studies," Advanced Materials Research, Vols. 133-134, pp. 229-234, 2010.

[7] E. Manning, L. Ramos, F. Fernandes, C. Sousa and M. Azenha, "Tube-Jack Testing for Irregular Masonry: Preliminary Testing," in 8th International Conference on Structural Analysis of Historical Constructions, Wroclaw, Poland, 2012.

[8] E. J. Hearn, "Ch. 10: Thick cylinders," in Mechanics of Materials 1: An Introduction to the Mechanics of Elastic and Plastic Deformation of Solids and Structural Materials - 3rd ed., Woburn, MA, USA, ButterworthHeinemann, 1997, pp. 215-253.

[9] EN 1052-1, "Methods of test for masonry - Part 1: Determination of compressive strength.," 1999.

[10] E. Manning, L. F. Ramos and F. Fernandes, "Direct Sonic and Ultrasonic Wave Velocity in Masonry under Compressive Stress," in 9th International Masonry Conference, Guimaraes, Portugal, 2014.

[11] Standard Test Methods for Vulcanized Rubber and Thermoplastic Elastomers- Tension, ASTM Standard D412, 1998. 
